\title{
Microtensile and Microshear Bond Strength of an Antibacterial Self-Etching System to Primary Tooth Dentin
}

Sibel Yıldırıma, DDS, PhD

Gül Tosun' ${ }^{b}$ DDS, PhD

Alp Erdin Koyutürkc, DDS, PhD

Yaḡmur Senera, DDS, PhD

Abdulkadir Sengünd, DDS, PhD

Füsun Özere, DDS, PhD

Satoshi Imazato ${ }^{\dagger}, \mathrm{PhD}$

\section{ABSTRACT}

Objectives: The aim of this study was to test the hypothesis that the bonding ability of antibacterial bonding system to primary dentin was not different from the parental material which did not contain any antibacterial component.

Methods: Extracted human non-carious primary molars were ground to expose the coronal dentin, and then randomly divided into two experimental groups: treatment with Clearfil Protect Bond or with Clearfil SE Bond (Kuraray Medical Inc.). Composite-dentin sticks with a cross-sectional area of approximately $0.90 \mathrm{~mm}^{2}$ were prepared and subsequently subjected to microtensile bond strength ( $\mu \mathrm{TBS}$ ) and microshear bond strength ( $\mu \mathrm{SBS}$ ) tests. For the $\mu$ TBS tests, specimens were attached to an Instron testing machine with a cyanoacrylate adhesive. For $\mu$ SBS testing, the sticks were mechanically fixed to the $\mu$ SBS testing apparatus. The bonds were stressed in shear or tension at a crosshead speed of $1 \mathrm{~mm} / \mathrm{min}$ until failure occurred. Resin-dentin interfaces produced by each system were examined using SEM. The data were analyzed with Mann-Whitney's U test.

Results: The $\mu$ TBS and $\mu$ SBS of Clearfil Protect Bond were $30.69 \pm 9.71$ and $9.94 \pm 3.78 \mathrm{MPa}$, respectively. Clearfil SE Bond showed significantly greater values of $37.31 \pm 9.57$ and $12.83 \pm 3.15$ $\mathrm{MPa}$, respectively. SEM analysis demonstrated similar micro-morphological features including the thickness of the hybrid layer for both materials.

Conclusions: It was showed that antibacterial self-etching system Clearfil Protect Bond showed lower bond strength values compared to primary dentin than that of to Clearfil SE Bond on primary dentin. (Eur J Dent 2008;2:11-17)

Key words: Primary tooth dentin; Microshear bond strength; Microtensile bond strength; Antibacterial bonding system.

n associate professor, Selcuk University, Faculty of Dentistry, Department of Pediatric Dentistry, Konya, Turkey.

b Assistant professor, Selcuk University, Faculty of Dentistry, Department of Pediatric Dentistry, Konya, Turkey.

Assistant professor, On Dokuz Mayıs University, Faculty of Dentistry, Department of Pediatric Dentistry, Samsun, Turkey.

d Associate professor, Selcuk University, Faculty of Dentistry, Department of Conservative Dentistry, Konya, Turkey.

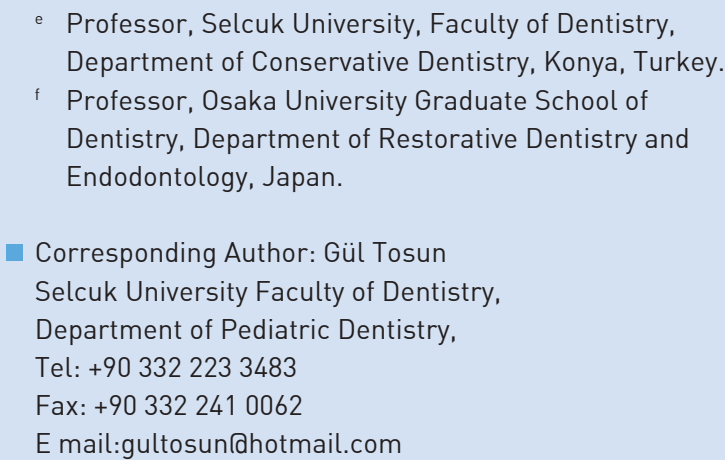




\section{INTRODUCTION}

Based on the principles of minimal invasive dentistry, much attention has recently been focused on the least invasive method for caries treatment. However, it is possible that some active bacteria remain after minimal removal of the effected dentin by leaving affected dentin. It is well known that residual bacteria in the prepared cavity can induce recurrent caries and damage to the pulp. Therefore, if the materials applied after cavity preparation possesses antibacterial activity, any indistinct bacterial conditions remaining in the cavity might be overcome, thus contributing to successful restoration. In addition, bacterial leakage through the gap between the restorative material and cavity wall is the main cause of hypersensitivity. ${ }^{1,2}$ As one solution to these problems, adhesive systems that exert antibacterial effects have been highlighted. ${ }^{3}$

Dentin adhesives are now widely used in clinical dentistry, andimproved ornewversions, whichclaim to offer advantages over their predecessors, are constantly being introduced. Self-etching adhesive systems are beneficial for pediatric dentistry practice as well as treatment of adult patients, because the bonding procedures are simplified and technique sensitivity is reduced. Imazato et $\mathrm{al}^{4,5}$ reported that incorporation of the antibacterial monomer 12-methacryloyloxydodecylpyridinium bromide (MDPB) to self-etching primers is an effective method for providing antibacterial activity before and after polymerization. MDP-based primer containing MDPB has been suggested to be useful for both eliminating residual bacteria in the prepared dentinal cavity ${ }^{6,7}$ and inhibiting invading bacteria at the resin-dentin interface after placement of the restoration. Although the adhesive property of this new system to primary enamel has been investigated, ${ }^{8}$ little is known about its bonding ability to dentin of primary teeth. This study investigated the bonding performance of the MDPB-containing antibacterial selfetching system to primary teeth dentin by means of microtensile/microshear test methods and morphological observations of the bonding interface. The hypothesis that the incorporation of MDPB would not alter the bonding characteristics of the adhesive resin was tested.

\section{MATERIALS AND METHODS}

Specimen preparations

Ten extracted human non-carious primary molars were used. Teeth were stored at $4^{\circ} \mathrm{C}$ in saline solution containing $0.1 \%$ thymol and used within three months following extraction. The occlusal surfaces of the teeth were cut just below the dentino-enamel junction to expose a flat area of dentin using a low-speed diamond saw (Isomet, Buehler Ltd, Lake Bluff, IL, USA) under watercooling. The dentin surfaces were hand-polished with 600grit silicon carbide abrasive paper under running water to create a uniform surface and smear layer. Then, the teeth were randomly divided into two groups for treatment with either Clearfil Protect Bond (PB, Kuraray Medical Inc., Okayama, Japan) or Clearfil SE Bond (SE, Kuraray Medical Inc., Okayama, Japan) (Table 1). PB consists of a self-etching primer containing the antibacterial monomer MDPB and a fluoride-releasing bonding resin. Following application of each adhesive according to the manufacturer's instructions, the surface was built up with three layers of resin composite (Clearfil AP-X, Kuraray Medical Inc., Okayama, Japan) to a height of $5 \mathrm{~mm}$ with light curing of each increment for $40 \mathrm{sec}$. The samples were then stored in water at $37^{\circ} \mathrm{C}$ for $24 \mathrm{~h}$.

\section{Bond strength tests}

The roots of the teeth were removed approximately $2 \mathrm{~mm}$ below the cementoenamel junction then the remaining dentin-resin composite blocks were vertically sectioned into $1 \times 1 \mathrm{~mm}$ sticks by means of a low-speed diamond saw under watercooling according to the technique for the non-trimming version of the microtensile bond test reported by Sano et al. ${ }^{9}$ Each sample had a cross-sectional area of $0.90 \pm 0.05 \mathrm{~mm}^{2}$.

For the microtensile bond strength ( $\mu$ TBS) tests, specimens were attached to an Instron testing machine (Dillon, Tronix Inc. MN 56031-1000 Instron Drive Fairmont, USA) with a cyanoacrylate adhesive. Tensile forces were applied to the composite dentine attachment line at a crosshead speed of $1 \mathrm{~mm} / \mathrm{min}$ until failure occurred. For determination of microshear bond strength ( $\mu \mathrm{SBS}$ ), samples were mechanically fixed to the microshear bond testing apparatus (Figure 1), and forces were applied to the composite-dentin 
bonded line at a cross head speed of $1 \mathrm{~mm} / \mathrm{min}$. The bond strengths were expressed in MPa after measuring the cross-sectional area at the site of fracture with digital calipers (Mitutoyo, Tokyo, Japan). Fifteen specimens were tested for each group.

\section{Fracture analysis}

After the $\mu$ TBS and $\mu$ SBS tests, the fractured surfaces were examined using a stereomicroscope (Olympus SZ 4045 TRPR, Tokyo, Japan) at x20 magnification. Failure modes were categorized into one of three types:

adhesive failure, if less than $20 \%$ of the resin remained on the tooth surface;

cohesive failure, if more than $80 \%$ of the resin remained on the tooth surface;

n or mixed failure, if certain areas exhibited cohesive fracture while other areas exhibited adhesive fracture.

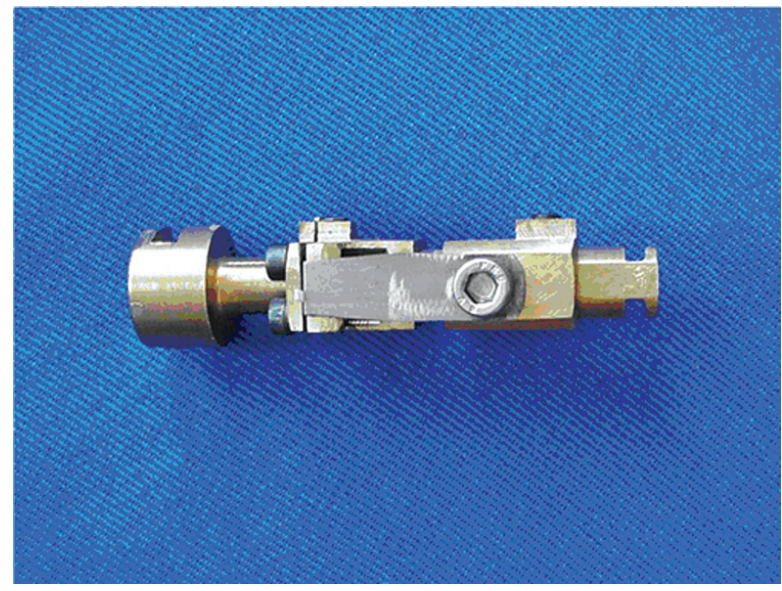

Figure 1. Microshear bond testing apparatus
Scanning electron microscopy (SEM) evaluation

Two additional primary teeth were used to evaluate the morphology of the interface between the resin composite and dentin by SEM. After the composite was bonded to the PB or SEtreated dentin surface, the tooth was sectioned in two parallel to its long axis using a low speed diamond saw. The cut surfaces were ground with silicon carbide abrasive paper after being fixed in $10 \%$ formaldehyde solution for $24 \mathrm{~h}$, and highly polished with a diamond paste (Struers, Copenhagen, Denmark). Then, the specimens were immersed in $10 \%$ phosphoric acid solution for $3-5 \mathrm{sec}$. Following $15 \mathrm{sec}$ rinsing with distilled water, the specimens were subjected to $30 \mathrm{sec}$ treatment with $5 \%$ sodium hypochlorite solution, and rinsed thoroughly with distilled water. After drying at room temperature $\left(27^{\circ} \mathrm{C}\right)$, the specimens were coated with Polaron Sc500 Sputter Coater (VG Microtech Inc., Tokyo, Japan) and examined under SEM (JSM- 5600, JEOL, Tokyo, Japan) at an accelerating voltage of $20 \mathrm{keV}$.

\section{Statistical analysis}

The test for the homogeneity of variances revealed that the bond strength values were not distributed homogeneously $(P<.05)$, thus, the bond strength and fracture mode results were statistically analyzed by Mann-Whitney's U test at a confidence level of $95 \%$.

\section{RESULTS}

\section{Bond strength}

The results of $\mu$ TBS and $\mu$ SBS tests are shown in Table 2. Both materials exhibited $\mu$ TBS greater

Table 1. Manufacturers, components and application procedures of the adhesive systems used in this study.

\begin{tabular}{|c|c|c|c|}
\hline Adhesive systems & Components & Compositions & Procedures \\
\hline $\begin{array}{l}\text { Clearfil Protect Bond } \\
\text { (Kuraray Medical } \\
\text { Inc., Japan) }\end{array}$ & $\begin{array}{l}\text { Antibacterial primer } \\
\text { Fluoride releasing } \\
\text { bonding resin }\end{array}$ & $\begin{array}{l}\text { MDPB,MDP,HEMA, water, hydrophilic, } \\
\text { dimethacrylate, photoinitiators } \\
\text { MDP,HEMA, Bis-GMA, silinated } \\
\text { colloidal silica, surface treated NaF }\end{array}$ & a $(20 \mathrm{sec}), \mathrm{b}, \mathrm{c}, \mathrm{d}(10 \mathrm{sec})$ \\
\hline $\begin{array}{l}\text { Clearfil SE Bond } \\
\text { (Kuraray Medical } \\
\text { Inc., Japan) }\end{array}$ & Bonding resin & $\begin{array}{c}\text { MDP, HEMA, water, hydrophilic } \\
\text { dimeracyrlate } \\
\text { MDP, Bis-GMA, HEMA, hydrophilic } \\
\text { dimethacrylate, silinated colloidal } \\
\text { silica }\end{array}$ & a (20 sec), b, c, d (10 sec) \\
\hline
\end{tabular}

a:apply primer, b:dry gently, c:apply adhesive, d:light cure 
than 30MPa, but the bond strengths of SE were significantly higher than those of $\mathrm{PB}(\mathrm{P}<.05)$.

The modes of failure for each group are shown in Table 3. Failures were predominantly adhesive or cohesive in nature; mixed failures were not recorded in any specimen. With the $\mu$ TBS tests, all PB specimens demonstrated adhesive failure, while $66.7 \%$ adhesive and $33.3 \%$ cohesive failure were observed for SE. Adhesive failure occurred in 14 PB specimens (93.3\%), but the SE specimens demonstrated $53.3 \%$ adhesive and $46.7 \%$ cohesive failure for the $\mu$ SBS tests. The type of dentine cohesive was not observed.

\section{SEM observations}

Figures 2 and 3 indicate the resin-dentin interface produced by each adhesive system. The bonded interfaces of both systems presented similar micro-morphological features including a resin infiltration layer (hybrid layer) and resin tag formation. The thickness of the hybrid layer was approximately $1 \mu \mathrm{m}$ and penetration of many resin tags more than $40 \mu \mathrm{m}$ in length was observed.

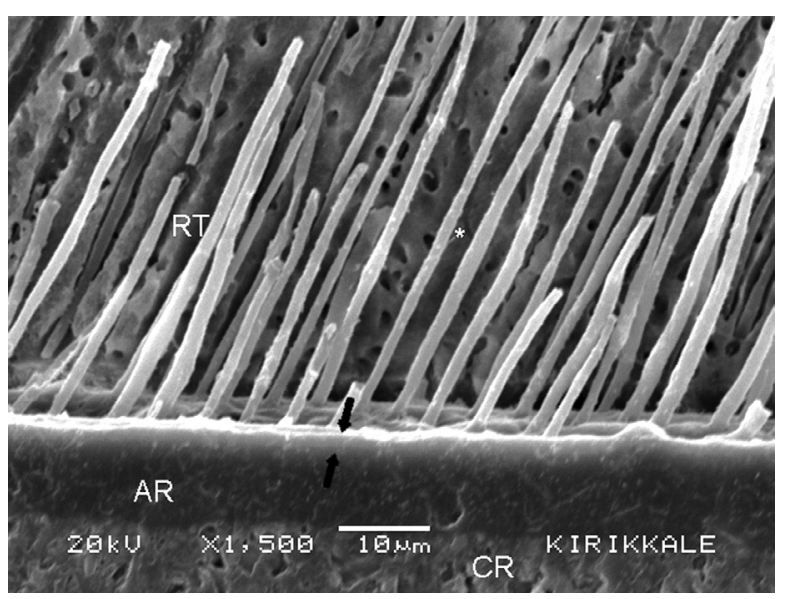

Figure 2. SEM illustrating the resin-dentin interface of $A B F$ $A R=$ Adhesive Resin; $C R=$ Composite Resin; $R T=$ Resin Tag; asterisk= Lateral Branches; between the black arrows= Hybrid layer

Table 2. The microtensile ( $\mu \mathrm{TBS}$ ) and microshear bond strength ( $\mu \mathrm{SBS}$ ) values in MPa of each adhesive system to primary dentin.

\begin{tabular}{lccc}
\cline { 3 - 4 } & & PB(Clearfil Protect Bond) & SE(Clearfil SE Bond) \\
\hline \multirow{2}{*}{$\mu$ TBS(MPa) } & Mean \pm SD & $30.69 \pm 9.71 \mathrm{a}$ & $37.31 \pm 9.57 \mathrm{~b}$ \\
& Median & 33.95 & 41.57 \\
\hline \multirow{2}{*}{$\mu$ SBS(MPa) } & Mean $\pm S D$ & $9.94 \pm 3.78 \mathrm{c}$ & $12.83 \pm 3.15 \mathrm{~d}$ \\
& Median & 12.43 & 9 \\
\hline
\end{tabular}

Statistically significant differences were observed between groups with different superscript letter $(P<.05)$

\section{DISCUSSION}

Microtensile bond test, developed by Sano et al $^{9}$ utilize a small bonding interface in the order of $1 \mathrm{~mm}^{2}$ and are commonly used to compare the adhesive abilities of different adhesive systems. In addition, the microshear bond test was recently suggested as being a useful method for investigating adhesive abilities. ${ }^{10}$ Therefore, in this study, the bond strengths of PB and SE to primary teeth dentin were compared using these two methods.

Our results indicated that the $\mu$ TBS and $\mu$ SBS of PB were significantly less than those of SE, which means incorporation of the antibacterial monomer MDPB to the self-etching primer cause a decrease in bond strength to primary teeth dentin. Kameyama et al $^{11}$ reported that the PB system showed significantly lower bond strengths than SE to bovine dentin, and concluded that this decrease might have been due to the bonding resin of $\mathrm{PB}$ rather than the MDPB-containing selfetching primer. The bonding resin of $P B$ contains sodium fluoride, which gives it a fluoride-releasing

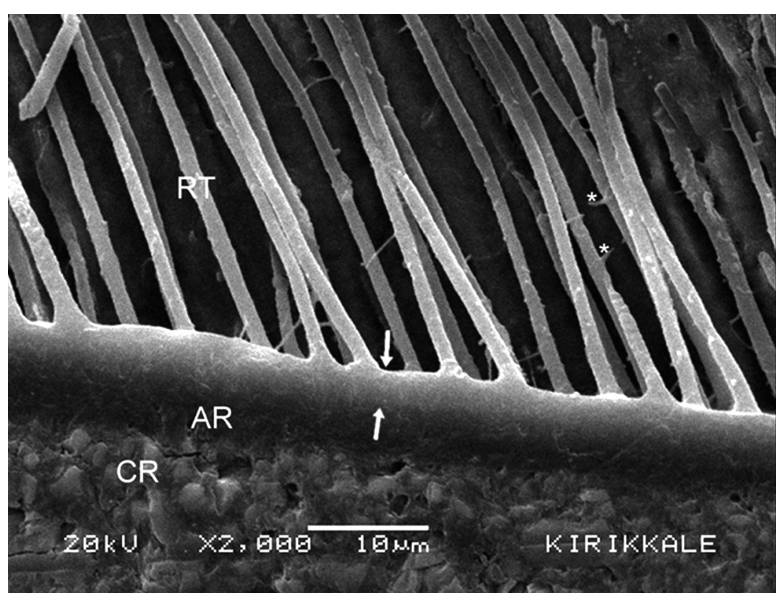

Figure 3. SEM illustrating the resin-dentin interface of Clearfil $\mathrm{SE}$ Bond. $\mathrm{AR}=$ Adhesive Resin; $\mathrm{CR}=$ Resin Composite; $\mathrm{RT}=$ Resin Tag; asterisks= Lateral Branches; between the white arrows= Hybrid layer 
function, and its viscosity is slightly greater than the bonding resin of SE. ${ }^{12}$ Imazato et a ${ }^{13}$ suggested that the viscosity of adhesive resin was increased by the addition of a large amount of MDPB, the concentration of MDPB incorporation was set at $2.5 \%$ as the maximum value. While the handling characteristics were not hampered, they speculate that a slight decrease, although not significant, of bond strength with experimental adhesive might be derived from inferior infiltration of the resin into the primed dentin due to a slight increase in the viscosity.

We used thymol as storage medium and this might cause lower bond strengths as it has been shown that phenolic compounds such as thymol inhibit the polymerization of methyl methacrylate by reacting with free radicals. ${ }^{14}$

As it is known, the bonding mechanism of adhesive systems to dentin is micromechanical, essentially based on infiltration of resin components into the etched dentin surface and subsequent formation of a resin infiltration layer (hybrid layer), resin tags, and adhesive lateral branches..$^{15}$ In addition, self-etch adhesive systems partially demineralise the dentin surface and simultaneously infiltrate resin monomer into the dentin matrix, resulting in the creation of a hybrid layer containing scattered apatite crystals. The acidic functional monomer present in the self etching primer may interact with $\mathrm{Ca}$ ions to form insoluble Ca salts. ${ }^{16}$ The crystalline characteristic of the dentin matrix may affect the bond strength of self-etch adhesive systems. The presence of solubilised $\mathrm{Ca}$ within the partially demineralised zone may promote chemical interactions with acidic functional monomers. ${ }^{17}$ SEM observations indicated almost similar interfacial morphology for both adhesive systems including the thickness of the hybrid layer and length of the resin tags. Since in-vitro tags are known to be longer than the ones produced in-vivo, observed long tags in the study

Table 3. The number and percentage of specimens categorized into the three fracture modes.

\begin{tabular}{|c|c|c|c|c|}
\hline & & Adhesive(\%) & Cohesive(\%) & $\operatorname{Mix}(\%)$ \\
\hline \multirow{2}{*}{ PB } & $\mu$ TBS test & $15(100)$ & 0 & 0 \\
\hline & $\mu S B S$ test & 14(93.3) & $1(6.7)$ & 0 \\
\hline \multirow{2}{*}{ SE } & $\mu$ TBS test & $10(66.7)$ & $5(33.3)$ & 0 \\
\hline & $\mu S B S$ test & $8(53.3)$ & $7(46.7)$ & 0 \\
\hline
\end{tabular}

were not expected to add to the bond strength. ${ }^{18}$

Under conventional tensile and shear bond tests, stressed specimens often demonstrate cohesive failure in the dentin or resin material. On the other hand, cohesive fractures are not observed clinically with adhesive restorations.? The number of cohesive fractures in dentin was significantly reduced when a microtensile bond test was performed. ${ }^{9}$ Pashley et al ${ }^{19}$ suggested that the small size of the specimens led to a more favourable stress distribution and thus failure, which more closely represented the true ultimate strengths. Nevertheless, De Munck et $\mathrm{al}^{20}$ and Doi et $a^{21}$ reported that adhesive failure seldom occurred in $\mu$ TBS tests of PB using permanent dentin. This fact indicates the strong bonding characteristics of PB to permanent dentin. On the contrary, PB demonstrated adhesive failure in almost all the specimens following microtensile and microshear testing in this study.

In the present $\mu$ TBS tests, the specimens were placed passively in a jig to ensure that there was no preloading stress, and with $\mu$ SBS testing, the shear force was applied by a stubby edge blade. With permanent teeth, a wide variety of $\mu$ TBS results have been reported for $\mathrm{SE},{ }^{22,23}$ possibly due to differences in the methodology such as the test apparatus. ${ }^{24}$ For $\mu$ SBS testing, many different configurations including wire loops, points or knife edges have been reported. ${ }^{10,25}$ Therefore, although precise comparisons of our results with those of previous studies are not possible, we found that the bond strengths of PB and SE to dentin of primary teeth were generally lower compared with those reported for permanent dentin..$^{20,21,26}$ Several differences in chemical composition or micromorphology exist between dentin of primary and permanent teeth. ${ }^{27}$ Peritubular dentin of primary teeth is 2-5 times thicker than that of permanent teeth ${ }^{28}$ and permanent dentin is more highly mineralized than primary teeth. ${ }^{29}$ Micromorphological analysis of primary teeth showed a lower density and diameter of dentinal tubules, therefore the permeability of primary dentin is less than that of permanent dentin. ${ }^{30}$ Olmez et $\mathrm{al}^{31}$ reported that the hybrid layer produced in primary teeth was thicker than in permanent teeth. It was concluded by Burrow et $\mathrm{al}^{32}$ that the major reason for a decrease in bond strengths in primary teeth is the greater 
water content in dentin approximating the pulp, not variations in the structure of surface area of intertubular dentin. These differences between primary and permanent teeth are thought to be responsible for lower bond strength. ${ }^{29,30}$

In the present study, although the same materials were used, the microshear tests showed lower values than the microtensile tests. Kitasako et al $^{33}$ reported significant differences in bond strengths of resin cements adhered to dentin when the shear and tensile testing methods were compared. The differences in the results of these micro-bond tests are thought to have arisen from differing force directions and the resulting stress distribution pattern at the interface. ${ }^{34,35}$ The advantages of both methods require investigation if the most reliable universal testing method is to be determined.

Our hypothesis was the bonding ability of PB to primary dentin is not different from that parental material (SE Bond) and the results of this study showed that $\mu$ TBS and $\mu$ SBS of PB are about $17 \%$ and $23 \%$ lower compared to SE Bond to primary teeth dentin, respectively. Thus, the hypothesis was rejected. The basic concept behind self-etching primers is that demineralization of the tooth structure and diffusion of the bonding agent around dentinal collagen fibers occur simultaneously and to the same depth. ${ }^{18}$ MDPB has a potential to be incorporated into dental resin-based materials such as dentin bonding primer/resin to provide bactericidal activity without causing adverse effect on biocompatibility. ${ }^{37}$ On the other hand, variations in bond strength can reflect a number of factors, such as specimen storage medium, bond strength test used and the different content of the materials. Further clinical trials are therefore required to confirm the data obtained from this laboratory study and to establish the value of antibacterial self etching bonding system under clinical situations of pediatric dentistry.

\section{CONCLUSIONS}

It was showed that antibacterial self-etching system Clearfil Protect Bond showed lower bond strength values compared to primary dentin than that of to Clearfil SE Bond on primary dentin.

\section{ACKNOWLEDGMENTS}

This study was supported by The Scientific
Research Committee of Selcuk University with grant number 2004/052 and a Grant-in-aid for Scientific Research $(15209066,16390545)$ from the Japan Society for the Promotion of Science.

\section{REFERENCES}

1. Bergenhotlz G, Cox CF, Loesche WJ, Syed SA. Bacterial leakage around dental restorations: its effect on the dental pulp. J Oral Pathol 1982;11:439-450.

2. Brännström M. The cause of postrestorative sensitivity and its prevention. J Endod 1986;12:475-481.

3. Imazato S. Antibacterial properties of resin composites and dentin bonding systems. Dent Mater 2003;19:449-457.

4. Imazato S, Ehara A, Torii M, Ebisu S. Antibacterial activity of dentin primer containing MDPB after curing. $J$ Dent 1998;26:267-271.

5. Imazato S, Kinomoto Y, Tarumi H, Torii M, Russell RRB, McCabe JF. Incorporation of antibacterial monomer MDPB in dentin primer. J Dent Res 1997;76:768-772.

6. Imazato S, Kaneko T, Takahashi Y, Noiri Y, Ebisu S. In vivo antibacterial effects of dentin primer incorporating MDPB. Oper Dent 2004;29:369-375.

7. Imazato S, Torii Y, Takatsuka T, Inoue K, Ebi N, Ebisu S. Bactericidal effect of dentin primer containing antibacterial monomer metacryloyloxydodecylpridium bromide (MDPB) against bacteria in human carious dentin. J Oral Rehab 2001;28:314-319.

8. Daronch M, De Goes MF, Grande RHM, Chan DCN. Antibacterial and conventional self-etching primer system: morphological evaluation of intact primary enamel. $J$ Clin Ped Dent 2003;27:251-256.

9. Sano H, Sonoda H, Shono T, Takatsu T, Ciucchi B, Carvalho R, Pashley D. Relationship between surface area for adhesion and tensile bond strength evaluation of a microtensile bond test. Dent Mater 1994;10:236-240.

10. Shimida Y, Senawongse P, Harnirattisai C, Burrow MF, Nakaoki Y, Tagami J. Bond strength of two adhesive systems to primary and permanent enamel. Oper Dent 2002;27:403-409.

11. Kameyama A, Shuto S, Muto Y, Sazuka H, Ushiki T, Hosaka M, Hirai Y. Studies on an MDPB-containing experimental resin bonding system-Part 1 Early bond strength of PB to bovine dentin. Jpn J Conservative Dent 2000;44:311-317.

12. Kubo S, Yokota H, Yokota H, Hayashi Y. Bond strengths and microleakage of new adhesive systems. In: Yoshiyama M, Nishitani Y, Nakabo S, Cox CF, eds. Modern Trends in Adhesive Dentistry Proceedings of the Adhesive Dentistry Forum 2001 in Okayama, Japan. Tokyo: Kuraray Medical Inc., 1999;15-29.

13. Imazato S, Kinomoto $Y$, Tarumi H, Ebisu S, Tay FR. 
Antibacterial activity and bonding characteristics of an adhesive resin containing antibacterial monomer MDPB. Dent Mater 2003:19:313-319.

14. Fujisawa S, Kadoma Y. Effect of phenolic compounds on the polymerization of methyl methacrylate. Dent Mater 1992;8:324-326.

15. Nakornchai S, Harnirattisai C, Surarit R, Thiradilok S. Microtensile bond strength of a total-etching versus selfetching adhesive to caries-affected and intact dentin in primary teeth. J Am Dent Assoc 2005;136:477-483.

16. Ikemura K, Tay FR, Hironaka T, Endo T, Pashley DH. Bonding mechanism and ultrastructural interfacial analysis of a single-step adhesive to dentin. Dent Mater 2003;19:707715.

17. Nakajima M, Ogata M, Harada N, Tagami J, Pashley DH. Bond strengths of self-etching primer adhesives to in vitrodemineralized dentin following mineralizing treatment. $J$ Adhes Dent 2000;2:29-38.

18. Ferrari M, Vichi A, Grandini S. Efficacy of different adhesive techniques on bonding to root canal walls: a SEM investigation. Dent Mater 2001;17:422-429.

19. Pashley DH, Sano H, Ciucchi B, Yoshiyama M, Carvalho RM. Adhesion testing of dentin bonding agents: a review. Dent Mater 1995;11:117-125.

20. De Munck J, Van Meerbeek B, Inoue S, Vargas M, Yoshida Y, Armstrong S, Lambrechts P, Vanherle G. Microtensile bond strengths of one- and two-step self-etch adhesives to bur-cut enamel and dentin. Am J Dent 2003;16:414-420.

21. Doi J, Itota T, Yoshiyama M, Tay FR, Pashley DH. Bonding to root caries by a self-etching adhesive system containing MDPB. Am J Dent 2004; 17:89-93.

22. Abdalla Al. Microtensile and tensile bond strength of single-bottle adhesives: a new test method. J Oral Rehabil 2004;31:379-384.

23. Takahashi A, Sato Y, Uno S, Pereira PN, Sano H. Effects of mechanical properties of adhesive resins on bond strength to dentin. Dent Mater 2002;18:263-268.

24. Fowler CS, Swartz ML, Moore BK, Rhodes BF. Influence of selected variables on adhesion testing. Dent Mater 1992;8:265-269

25. McDonough WG, Antonucci JM, He J, Shimada Y, Chiang MY, Schumacher GE, Schultheisz CR. A microshear test to measure bond strengths of dentin-polymer interfaces. Biomaterials 2002;23:3603-3608.

26. Chan KM, Tay FR, King NM, Imazato S, Pashley DH. Bonding of mild self-etching primers/adhesives to dentin with thick smear layers. Am J Dent 2003;16:340-346.

27. Sumikawa DA, Marshall GW, Gee L, Marshall S. Microstructure of primary tooth dentin. Pediatr Dent 1999;21:439-444.
28. Hirayama A, Yamada M, Miake K. An electron microscopic study on dentinal tubules of human deciduous teeth. Shika Gakuho 1986;86:1021-1031.

29. Johnsen DC. Comparison of primary and permanent teeth In: Avery JA, eds. Oral development and histology. Philadelphia:BC Decker, 1999;180-190.

30. Koutsi V, Noonan RG, Horner JA, Simpson MD, Matthews WG, Pashley DH. The effect of dentin depth on the permeability and ultrastructure of primary molars. Pediatr Dent 1994;16:29-35.

31. Olmez A, Oztas N, Basak F, Erdal S. Comparison of the resin dentin interface in primary and permanent teeth. $J$ Clin Pediatr Dent 1998;22:293-298.

32. Burrow MF, Nopnakeepong U, Phrukkanon. A comparison of microtensile bond strengths of several dentin bonding systems to primary and permanent dentin. Dent Mater 2002; 18:239-245.

33. Kitasako Y, Burrow MF, Nikaido T, Harada N, Inokoshi S, Yamada T, Takatsu T. Shear and tensile bond testing for resin cement evaluation. Dent Mater 1995;11:298-304.

34. Van Noort R, Cardew GE, Howard IC, Noroozi S. The effect of local geometry on the measurement of tensile bond strength to dentin. J Dent Res 1991;70:889-893.

35. Van Noort R, Noroozi S, Howard IC, Cardew GE. A critique of bond strength measurements. J Dent 1989;17:61-67.

36. Nakabayashi N, Pashley DH. Hybridization of dental hard tissues. Tokyo: Quintessence Publishing Co. Ltd. 1998; 34.

37. Imazato S, Ebi N, Tarumi H, Russell RR, Kaneko T, Ebisu S. Bactericidal activity and cytotoxicity of antibacterial monomer MDPB. Biomaterials 1999;20:899-903. 